\title{
Synthesis, Spectral Characterization Antimicrobial Activity and DFT Studies of Some Tetrahydropyrimidinones ${ }^{+}$
}

\author{
Maria Marinescu 1,*, Christina-Marie Zălaru 1, Anamaria Hanganu 2, Cristina Stavarache ${ }^{2}$ and \\ George Iuliu Marton ${ }^{3}$ \\ 1 Department of Organic Chemistry, Biochemistry and Catalysis, University of Bucharest, \\ 90-92 Soseaua Panduri, RO-050663 Bucharest, Romania; chmzalaru@gmail.com \\ 2 Institute of Organic Chemistry “C.D. Nenitzescu”, 202B Spl Independentei, RO-060023 Bucharest, Romania; \\ anamaria_hanganu@yahoo.com (A.H.); crisstavarache@gmail.com (C.S.) \\ 3 Department of Organic Chemistry, University "Politehnica" of Bucharest, 1-7 Polizu bd., \\ RO-011061 Bucharest, Romania; geo_marton@yahoo.com \\ * Correspondence: maria.marinescu@chimie.unibuc.ro or maria7marinescu@yahoo.com \\ + Presented at the 16th International Symposium "Priorities of Chemistry for a Sustainable Development" \\ PRIOCHEM, Bucharest, Romania, 28-30 October 2020.
}

Published: 11 November 2020

Keywords: organic synthesis; tetrahydropyrimidines; NMR spectroscopy; density functional theory (DFT)

Dihydropyrimidine and tetrahydropyrimidine derivatives are pivotal heterocycles in medicinal chemistry. The reaction most often involved in the synthesis of these compounds is the multicomponent synthesis of Biginelli, which has been improved over the years [1].

Organic commercial and synthetic materials were used for the synthesis of the heterocyclic compounds. All compounds were characterized with physicochemical techniques (elemental analysis, 1H, 13C, FTIR and UV-Vis spectroscopy).

In this study a series of tetrahydropyrimidinones were synthesized in two steps: 1 . Biginelli synthesis [2]; 2. alkylation of intermediates from step 1. The structures of all compounds were confirmed by $1 \mathrm{H}, 13 \mathrm{C}-\mathrm{NMR}$, FTIR, UV-VIS spectra and elemental analysis. A DFT analysis of molecular structure and frontier molecular orbitals HOMO-LUMO was performed using the GAMESS 2012 software [3-6]. All compounds were evaluated by qualitative and quantitative methods against a panel of selected bacterial and fungal strains.

It was found that the presence of nucleophilic group and symmetry of the molecule are advantages for a high antimicrobial activity.

\section{References}

1. Kappe, C.O. 100 Years of the Biginelli dihydropyrimidine synthesis. Tetrahedron Lett. 1993, 49, 6937-6963, doi:10.1016/s0040-4020(01)87971-0.

2. Marinescu, M.; Berea, E.; Neculae, A.F.V.; Stavarache, C.E.; Hanganu, A.; Zalaru, C.M.; Marton, G.I. Synthesis, biological screening and DFT studies of the new tetrahydropyrimidine-benzo[d]imidazol compounds. Arch. Chem. Res. 2018, 2, 33, doi:10.21767/2572-4657-C4-012.

3. Marinescu, M.; Emandi, A.; Marton, G.; Cinteza, L.O.; Constantinescu, C. Structural studies and optical nonlinear response of some pyrazole-5-ones. Nanosci. Nanotechnol. Lett. 2015 7, 846-854, doi:10.1166/ nnl.2015.2032. 
4. Marinescu, M.; Tudorache, D.G.; Marton, G.; Zalaru, C.; Popa, M.; Chifiriuc, C.M.; Constantinescu, C. Synthesis, DFT study and antimicrobial features of some benzimidazole derivatives. J. Mol. Struct. 2017, $1130,463-471$.

5. Marinescu, M.; Cinteza, L.O.; Marton, G.I.; Marutescu, L.G.; Chifiriuc, C.M.; Constantinescu, C. Density functional theory molecular modeling and antimicrobial behaviour of selected 1,2,3,4,5,6,7,8octahydroacridine-N(10)-oxides. J. Mol. Struct. 2017, 1144, 14-23.

6. Marinescu, M.; Tablet, C.; Potmischil, F.; Hillebrand, M. Experimental and theoretical study of the interaction of 3-carboxy-5,6-benzocoumarin with some 1,2,3,4,5,6,7,8-octahydroacridines and the corresponding N-oxides. Spectrochim. Acta A 2011, 81, 560-569, doi:10.1016/j.saa.2011.06.051.

Publisher's Note: MDPI stays neutral with regard to jurisdictional claims in published maps and institutional affiliations.

(C) 2020 by the authors. Licensee MDPI, Basel, Switzerland. This article is an open access article distributed under the terms and conditions of the Creative Commons Attribution (CC BY) license (http://creativecommons.org/licenses/by/4.0/). 